\title{
Practice of One Health approaches: Bridges and barriers in Tanzania
}

\author{
Authors: \\ Kim A. Kayunze ${ }^{1,2}$ \\ Angwara Kiwara ${ }^{3}$ \\ Eligius Lyamuya ${ }^{4}$ \\ Dominic M. Kambarage ${ }^{5}$ \\ Jonathan Rushton ${ }^{6}$ \\ Richard Coker? \\ Richard Kock $^{8}$ \\ Affiliations: \\ ${ }^{1}$ Rural Development, Sokoine \\ University of Agriculture, \\ Tanzania \\ ${ }^{2}$ Southern African Centre \\ for Infectious Disease \\ Surveillance, Sokoine \\ University of Agriculture, \\ Tanzania \\ ${ }^{3}$ Development Studies, \\ Muhimbili University of \\ Health and Allied Sciences \\ (MUHAS), Institute of \\ Development Studies, \\ Tanzania
}

${ }^{4}$ Microbiology and Deputy Vice Chancellor (Academics, Research and Consultancy), Muhimbili University College of Health and Allied Sciences (MUHAS), Tanzania

${ }^{5}$ Veterinary Medicine, Sokoine University of Agriculture, Tanzania

${ }^{6}$ Animal Health Economics, Royal Veterinary College, United Kingdom

${ }^{7}$ Public Health, London School of Hygiene \& Tropical Medicine, United Kingdom

${ }^{8}$ Wildlife Health and Emerging Diseases, CEEED, Royal Veterinary College, United Kingdom

\section{Correspondence to:}

Kim Kayunze

Email:

kimkayunze@yahoo.com

Postal address:

PO Box 3024, Morogoro,

Tanzania

Read online:

Scan this $Q R$ code with your smart phone or mobile device to read online.
The practice of One Health approaches in human and animal health programmes is influenced by type and scope of bridges for and barriers to partnerships. It was thus essential to evaluate the nature and scope of collaborative arrangements among human, animal and wildlife health experts in dealing with health challenges which demand intersectoral partnership. The nature of collaborative arrangement was assessed, and the respective bridges and barriers over a period of 12 months (July 2011 - June 2012) were identified. The specific objectives were to: (1) determine the proportions of health experts who had collaborated with other experts of disciplines different from theirs, (2) rank the general bridges for and barriers to collaboration according to the views of the health experts, and (3) find the actual bridges for and barriers to collaboration among the health experts interviewed. It was found that $27.0 \%$ of animal health officers interviewed had collaborated with medical officers while $12.4 \%$ of medical officers interviewed had collaborated with animal health experts. Only $6.7 \%$ of the wildlife officers had collaborated with animal health experts. The main bridges for collaboration were instruction by upper level leaders, zoonotic diseases of serious impact and availability of funding. The main barriers to collaboration were lack of knowledge about animal or human health issues, lack of networks for collaboration and lack of plans to collaborate. This situation calls for the need to curb barriers in order to enhance intersectoral collaboration for more effective management of risks attributable to infectious diseases of humans and animals.

\section{Introduction}

One Health approaches in human and animal health programmes are much desired, and although their implementation is enhanced by some factors (bridges), it is impeded by other factors (barriers). The One Health Initiative (2011) defines these approaches as collaborative efforts of multiple disciplines working locally, nationally and globally to attain optimal health for people, animals, plants and our environment. The approaches have a long history which can be traced to the 1700s, when variolation was used by medical and non-medical people collaboratively to confer specific immunity to smallpox using cowpox (Riedel 2005).

One Health approaches have been being practised by various individuals and organisations. For example, in Tanzania, such collaboration exists between medical and veterinary officers who collaborate in prevention, diagnosis, control and treatment of rabies in people and in livestock. Other examples include sharing facilities such as refrigerators for storage of vaccines for humans and for livestock, and vehicles to carry out campaigns against zoonotic diseases. There is some empirical information on such collaborations; Karimuribo et al. (2012) found that sometimes animal and health officers in Ngorongoro District, Tanzania, were sharing vaccine storage facilities, especially during times of disease vaccination campaigns when teams of vaccinators were camping in remote rural areas. Although such collaborative activities are undertaken, upscaling the same and undertaking more others is impeded by various barriers. General barriers to as well as bridges for such collaboration are well documented, for example by the WHO (2006); however, the extent to which they enhance or impede the practice of One Health approaches are not known because no research has been done to generate such empirical information. Therefore, the research from which this article emanated was done with the specific objectives to: (1) determine the proportions of health experts who had collaborated with other experts of disciplines different from theirs, (2) rank the general bridges for and barriers to collaboration according to the views of the health experts, and (3) find the actual bridges for and barriers to collaboration among the health experts interviewed.

How to cite this article: Kayunze, K.A., Kiwara, A., Lyamuya, E., Kambarage, D.M Rushton, J, Coker, R et al, 2014, 'Practice of One Health approaches: Bridges and barriers in Tanzania', Onderstepoort Journal of Veterinary Research 81(2) Art. \#733, 8 pages. http:// dx.doi.org/10.4102/ojvr.v81i2.733

Note: Proceedings of the 2 nd One Health Conference in Africa. Jointly organised by the Southern African Centre for Infectious Disease Surveillance and the Tanzania National Institute for Medical Research, held at the Snow Crest Hotel in Arusha, Tanzania from 16th to 19th April 2013: http://www.sacids.org/kms/frontend/index.php?m=119.

Copyright: (C) 2014. The Authors. Licensee: AOSIS OpenJournals. This work is licensed under the Creative Commons Attribution License. 


\section{One Health practice: Historical background}

One Health is not new; its practice can be traced as far back as to the mid-1700s when Edward Jenner (17491823), honoured as the father of immunology, contributed innovatively to immunisation and the ultimate eradication of smallpox using cowpox to confer specific immunity to smallpox (Riedel 2005). The history of One Health is also associated with Rudolf Ludwig Karl Virchow (1821-1902), honoured as the father of pathology. His statement that 'politics is nothing else but medicine on a large scale' can be interpreted to mean that helping people on a one-to-one basis is called medicine and doing the same on a large scale is called politics. He also argued that 'between animal and human medicine there is no dividing line - nor should there be'. It is also he who coined the term 'zoonosis' (Kahn et al. 2007, cited by Monath, Kahn \& Kaplan 2010). He practised One Health by working in various disciplines, including human medicine, anthropology and public health. Another person who has contributed prominently to One Health is Calvin W. Schwabe (1927-2006) who, in 1964, coined the term 'One Medicine' (Schwabe 1969), now commonly called 'One Health', and proposed a unified human and veterinary approach to zoonotic diseases in his seminal textbook Veterinary Medicine and Human Health (1984). He promoted One Health by pioneering the use of human disease tracking techniques in the study of animal illnesses in the 1960s, and is honoured as the founder of veterinary epidemiology (World Bank 2010).

\section{One Health practice: Current situation}

The need for One Health practice is gaining popularity. Many feel that it should be practised to contain new diseases like Ebola haemorrhagic fever and avian influenza, which affect people and animals and quickly become pandemic. The increasing need for One Health has resulted in the formation of a global organ, One World - One Health (OWOH), in September 2004. OWOH has formulated twelve principles, known as the Manhattan Principles - which serve as recommendations for establishing a more holistic approach to preventing epidemic or epizootic diseases and for maintaining ecosystem integrity for the benefit of humans, their domesticated animals and the foundational biodiversity that supports humans (World Bank 2010). New diseases such as Ebola and avian flu remind us to be alert at all times as more hazardous diseases may appear at any time. Thus we can avoid the post-World War II complacency based on landmark medical attainments of the 1940s which were characterised by effective antimicrobial agents, along with the establishment of the principles and practice of immunisation. These attainments led George Marshall, United States Secretary of State at the time, to proclaim that the conquest of all infectious diseases was imminent which was not true since the relationships between people, microbes and environment are complex and ever changing (Coker, Atun \& McKee 2008).

Other organisations also promote One Health. The Wildlife Conservation Society (WCS), a non-governmental organisation based in the USA, fosters multidisciplinary research focusing on the interactions among human health, the environment, food and animal production. The Federation of Veterinarians of Europe (FVE), which was founded in 1975 (FVE n.d.), practises One Health with the aim to unite the European veterinary profession for the benefit of animal health, animal welfare and public health. In Africa, an organisation called Animal Health for the Environment and Development (AHEAD) practises One Health by focusing on several themes of critical importance to the future of animal agriculture, human health and livelihoods, and wildlife health and conservation (AHEAD n.d.).

Apart from these organisations, research projects in various parts of the world have focused on One Health. Mazet et al. (2009), for example, undertook a project in which they assessed the impact of interactions between water and disease in the Ruaha ecosystem by simultaneously investigating medical, ecological, socioeconomic and policy issues driving the system. However, some projects implementing One Health approaches have been short-lived and lacking capacity building components, which does not promote One Health on a sustainable basis. Unlike such projects, however, the Southern African Centre for Infectious Disease Surveillance (SACIDS) uses approaches that promote One Health on a long-term basis, including capacity building of current One Health workers through training and research (SACIDS n.d.).

Although One Health is advocated and is beginning to be adopted, it is practised by few organisations and people. Therefore, there have been appeals for more organisations and people to practise it. For example, the WHO (2006) argues that if it was adopted it would greatly facilitate detecting and dealing with zoonoses, while at the same time ensuring better access to health inputs for both poor people and their livestock. The WHO (2006) also proposes a framework for collaborative action to stem zoonoses, which has four components: (1) One Health: medical and veterinary, (2) research: epidemiology and new tools, (3) advocacy and information, and (4) diagnostics and surveillance. A strength of this framework is that it promotes the application of One Health principles. However, it overlooks the social ecosystem and the roles of socioeconomic and cultural aspects. An example is people's behaviour with regard to hunting and consuming bush-meat or close interaction with domestic animals, popular in sub-Saharan Africa and generally in the developing world, which may be a source of pathogens that may cause zoonotic diseases.

The WHO (2006) also suggests that neglected zoonotic diseases could be eradicated through diagnosis and surveillance by: using effective surveillance systems for each of the 'neglected zoonoses'; research on zoonoses with linkage to local public health systems; changing from single disease or vertical approach control measures to more integrated health promotion; and data sharing, monitoring and training, among other things. Neglected (or lingering) zoonoses are ancient diseases affecting both humans and animals (domestic and wild) which keep re- 
emerging as public problems for a number of reasons. The WHO (2006) lists the following lingering zoonoses and is concerned about the fact that they seem to attract less public awareness: anthrax, bovine tuberculosis, brucellosis, cysticercosis and neurocysticercosis, cystic echinococcosis or hydatid disease, rabies, zoonotic sleeping sickness or human African trypanosomiasis (HAT), and food-borne zoonoses including Salmonella (salmonellosis), Campylobacter (campylobacteriosis), and Escherichia coli infections of animal origin affecting millions of people annually.

Apart from various organisations promoting One Health, some individuals have advocated the adoption of One Health. Mahr (2006, cited by Winding 2007) says, for example:

Animal health is truly at a crossroads; its convergence with human and ecosystem health dictates that the 'one world, one health, one medicine' concept must be embraced. We need our colleagues in human medicine, public health, and the environmental health sciences. Together, we can accomplish more in improving global health than we can alone, and we have the responsibility to do so. (n.p.)

Although One Health is advocated and some organisations are applying its approaches, its practice is impeded by various barriers, some of which are well documented (see e.g. WHO 2006). The barriers and bridges are not listed here, but their relevance was evaluated in the research, and the extent to which they apply are reported on. Overcoming the barriers so as to increase collaboration by sharing responsibilities and coordinating global activities to address health risks, especially at the animal-human-ecosystems interface, could be on national agendas globally, and this can be facilitated internationally through the FAO, OIE and WHO. These organisations are committed to working more closely together to align activities related to the animal-humanecosystem interface in order to support member countries (FAO, OIE \& WHO 2010).

\section{Materials and methods}

This article is based on research conducted in Ngorongoro and Kibaha Districts of Tanzania in July 2012 and August 2012, covering the period from July 2011 to June 2012, whereby data were collected from 91 medical, veterinary and wildlife officers (51 medical officers, 30 veterinary officers and 10 wildlife officers). The officers were interviewed using a self-administered questionnaire, which they filled out in the presence of the researchers. The role of the latter was to clarify any items of the questionnaire in case the respondents needed clarification. The questionnaire was formulated with the aim to capture information on the respondents' collaboration among themselves, factors which enhanced collaboration and those which impeded collaboration. The respondents were selected purposively depending on their availability and them working in areas where households which were interviewed in the same study were receiving human and animal health services. Most of the respondents held diplomas, while a few held a Bachelor's degree and one held a Master's degree.
The two districts, Ngorongoro and Kibaha, were selected purposively because both have pastoralists who interact intimately with their livestock, and whose livestock interact with ecosystems and wildlife. These interactions are likely to enhance transmission of zoonotic diseases such as rabies, brucellosis, tuberculosis, and anthrax from wildlife to livestock and from livestock to people. For effective detection, prevention, control and treatment of such zoonoses, collaboration of medical, veterinary and wildlife officers would be important. The pastoralists of Kibaha District have originated from Northern Tanzania, including Ngorongoro District.

Permission to conduct the study was obtained from Sokoine University of Agriculture and endorsed by Ngorongoro and Kibaha District Executive Directors. Ethical consideration was observed as all participants were informed, before being interviewed, of the purpose of the study, what participation involved, confidentiality in the research, risks of participation, and their right to ask questions and withdraw from participation.

The data collected from the respondents were analysed using the Statistical Package for Social Sciences (SPSS) programme. Descriptive analysis was the main method of data analysis. Frequencies, percentages, averages and minimum and maximum values of individual variables were computed. The extent to which general factors enhance collaboration (bridges) and others constrain collaboration (barriers) among medical, veterinary and wildlife officers were determined using pair-wise ranking to compare 14 general factors enhancing collaboration and 14 general factors constraining collaboration. In each of the cases, factors enhancing or constraining collaboration were compared, two at a time, until every factor was compared with every other factor. Each time respondents were asked to give their view on which of the two was a more important factor. A dummy table (see Figure 1) is provided to illustrate how the comparison was done.

The numbers in Figure 1 represent the 14 factors enhancing or constraining collaboration; each of the statements has to be written twice. The shaded cells that are placed diagonally represent areas where an answer would be written if comparing a statement with itself would make sense; those cells as well as those below them are not used. Using the area below the shaded cells would result in duplication of information (of cells above them). The winning item of the two items that are compared is written in the cells above the shaded cells. Each of the fourteen factors in each case had the possibility of being mentioned at most 13 times, in other words, the first statement could win 13 times throughout the second row to the right of number 1; the last statement could win throughout the last column under number 14; and any other statement could win in its respective rows and columns a total number of 13 times. For example, Statement 5 could win four times in Column 6 (below 5) and 9 times in Row 6 to the right after the shaded cell in the row starting with 5 . The 


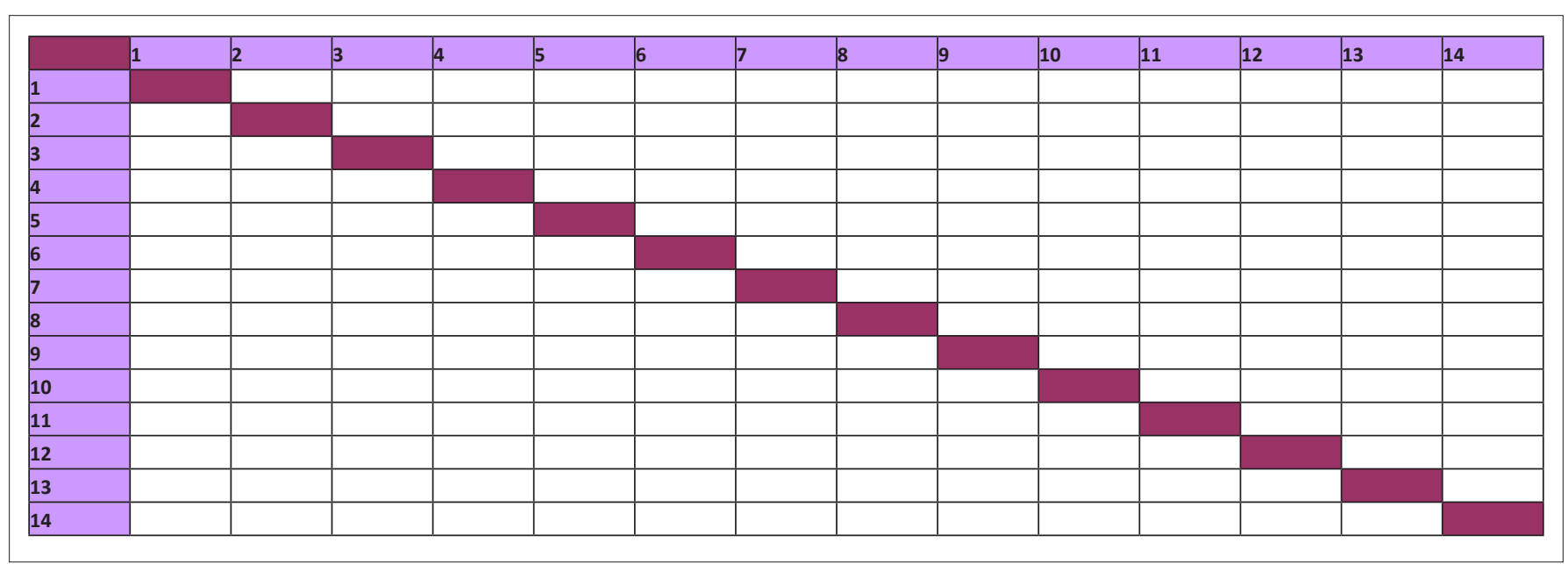

FIGURE 1: Tool used for pair-wise ranking of barriers and bridges.

average number of times each factor mentioned by all the respondents is expressed as a percentage of 13. The higher the percentage the more the important the factors are.

\section{Results}

The empirical information obtained from the respondents is reported in Table 1 with respect to whether they had been involved in any collaborative work with other experts in disease diagnosis, surveillance, treatment or control or conducting campaigns against specific diseases.

Using the procedure of pair-wise ranking described above, the results of the respondents' views on the extent to which general factors enhanced collaboration among medical, veterinary and wildlife officers are presented in Table 2.

By using pair-wise ranking, respondents were also asked to share their views on the extent to which general factors constrain collaboration (see Table 3).

Besides the general bridges and barriers stated above, which had been compiled before data collection, the respondents were asked about the actual bridges and barriers that impacted on their possible collaboration with health experts in other fields. The responses are summarised in Table 4.

\section{Discussion}

\section{Respondents' involvement in collaborative work with other experts}

The responses summarised in Table 1 regarding whether respondents had collaborated with experts from disciplines different from their own in the period 01 July 2011 to 30 June 2012 show that veterinary officers had collaborated with experts of other disciplines more than the other groups of experts, followed by medical officers. It is worth noting that collaboration took place even though there were no guidelines for collaboration. One could assume that if there were guidelines for collaboration, the level of collaboration would have been higher. The proportion of health experts who collaborated with health experts from other fields (as
TABLE 1: Proportions of health experts who had collaborated with other experts.

\begin{tabular}{|c|c|c|}
\hline \multirow[t]{2}{*}{ Collaboration among experts } & \multicolumn{2}{|c|}{ Responses } \\
\hline & $n$ & $\%$ \\
\hline $\begin{array}{l}\text { Human health experts who collaborated with animal health } \\
\text { experts }\end{array}$ & 11 & 12.4 \\
\hline Human health experts who collaborated with wildlife experts & 2 & 2.2 \\
\hline $\begin{array}{l}\text { Human health experts who collaborated with both animal } \\
\text { health and wildlife experts }\end{array}$ & 4 & 4.5 \\
\hline Subtotal & 17 & 19.1 \\
\hline $\begin{array}{l}\text { Animal health experts who collaborated with human health } \\
\text { experts }\end{array}$ & 24 & 27.0 \\
\hline Animal health experts who collaborated with wildlife experts & 16 & 18.0 \\
\hline $\begin{array}{l}\text { Animal health experts who collaborated with both human } \\
\text { health and wildlife experts }\end{array}$ & 16 & 18.0 \\
\hline Subtotal & 56 & 63.0 \\
\hline Wildlife experts who collaborated with human health experts & 5 & 5.6 \\
\hline Wildlife experts who collaborated with animal health experts & 6 & 6.7 \\
\hline $\begin{array}{l}\text { Wildlife experts who collaborated with both human health } \\
\text { and animal health experts }\end{array}$ & 5 & 5.6 \\
\hline Subtotal & 16 & 17.9 \\
\hline Total & 89 & 100 \\
\hline
\end{tabular}

seen in Table 1) were $19.1 \%, 63.0 \%$ and $17.9 \%$ for human health experts, animal health experts and wildlife experts respectively. This indicates a situation which can serve as a good starting point for up-scaling the practice of One Health approaches.

\section{Extent to which bridges enhance One Health practice}

The results presented in Table 2 show that the leading factors for enhancing collaboration were adequate transport facilities for medical, veterinary and wildlife officers (66.7\%), common training in zoonotic diseases for both veterinary and medical doctors and fieldworkers (59.0\%), One Health policy formulation guiding applied research in health (57.4\%), and advocacy for control of neglected zoonotic diseases $(55.9 \%)$. These leading factors are very realistic; for instance, the issue of One Health policy formulation or at least guidelines for mainstreaming One Health practices in human health and animal health systems can form a solid foundation on which to base plans for allocation of resources for One Health practice. Such plans and resource allocation are recommended by various researchers and academics, including Coker et al. (2008), Brazier et al. (2007) and Rushton 
TABLE 2: Views on extent to which general factors enhance collaboration.

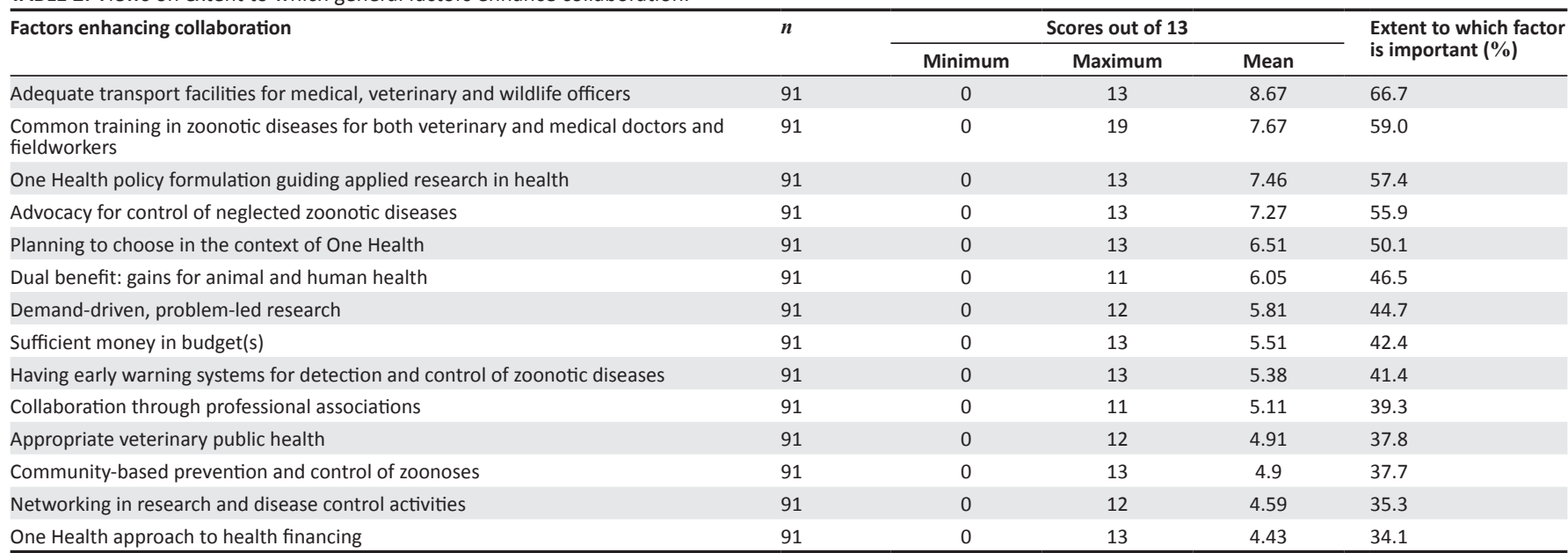

TABLE 3: Views on extent to which general factors constrain collaboration.

\begin{tabular}{|c|c|c|c|c|c|}
\hline \multirow[t]{2}{*}{ Factors constraining collaboration } & \multirow[t]{2}{*}{$n$} & \multicolumn{3}{|c|}{ Scores out of 13} & \multirow{2}{*}{$\begin{array}{l}\text { Extent to which factor } \\
\text { is important }(\%)\end{array}$} \\
\hline & & Minimum & Maximum & Mean & \\
\hline Lack of consensus on priority-setting & 91 & 0 & 12 & 8.45 & 65.0 \\
\hline Inadequate resources for dissemination of results and raising public awareness & 91 & 0 & 13 & 8.43 & 64.8 \\
\hline Applied research is not recognised or rewarded as being important as basic research & 91 & 0 & 12 & 7.22 & 55.5 \\
\hline Research is not demand driven but donor led & 91 & 0 & 13 & 6.53 & 50.2 \\
\hline Lack of resources & 91 & 0 & 13 & 6.11 & 47.0 \\
\hline Weak veterinary public health infrastructure & 91 & 0 & 12 & 5.42 & 41.7 \\
\hline Low emphasis on zoonotic diseases during training & 91 & 0 & 11 & 5.38 & 41.4 \\
\hline Budgetary separation: veterinary and medical costs not pooled & 91 & 0 & 13 & 5.37 & 41.3 \\
\hline Bureaucracy making decisions regarding human and health issues & 91 & 0 & 12 & 4.76 & 36.6 \\
\hline Lack of clarity about roles of public and private sector partners & 91 & 0 & 12 & 4.54 & 34.9 \\
\hline Control of zoonotic diseases is based on fire-fighting management & 91 & 0 & 12 & 3.98 & 30.6 \\
\hline $\begin{array}{l}\text { Institutional separation (e.g. between ministry of health and veterinary and } \\
\text { wildlife authorities) }\end{array}$ & 91 & 0 & 13 & 3.92 & 30.2 \\
\hline
\end{tabular}

et al. (2012). On the same issues, Coker et al. (2008) argue that lack of resources for health is mainly due to low resources allocation for strengthening public health capacity and recommend that the allocation of such resources should be understood as a cost-effective investment to support preparedness and resilience. On the other hand, Brazier et al. (2007) urge governments to allocate resources by policy making and by planning, especially once the judgement has been made that health care resources allocation cannot be left to unregulated markets. The judgement has to be based on empirical evidence; this is accentuated by Rushton et al. (2012) who conclude that:

Political reality of adopting a One Health agenda also requires thought and needs to be realistic with the evidence of added value from One Health approaches through systematic data collection and analysis. (n.p.)

On the same issue of judgement, Zinsstag et al. (2012) argue that claiming a One Health approach requires the demonstration of added value to what human and animal health working alone can achieve.

The above list of factors enhancing collaboration had been compiled before the survey. In addition, respondents were asked to mention other factors which they thought enhance or have the potential to enhance collaboration among various health experts. Sixty-two (62) of the respondents replied, giving the following responses: close relationship among experts $(29.0 \%)$, common training in zoonoses $(21.0 \%)$,

TABLE 4: Actual bridges and barriers.

\begin{tabular}{ll}
\hline Actual reasons & \% of responses \\
\hline $\begin{array}{l}\text { For collaboration } \\
\text { The disease(s) was or were (a) zoonosis or zoonoses }\end{array}$ & 26.4 \\
which needed assistance from veterinarians & \\
$\begin{array}{l}\text { The disease(s) was or were (a) zoonosis or zoonoses } \\
\text { which needed assistance from medical doctors }\end{array}$ & 25.5 \\
Instructed by upper-level leaders to cooperate & 22.7 \\
There was funding for the collaboration & 19.8 \\
Wildlife disease research & 1.9 \\
Transport & 1.9 \\
RVF outbreak & 0.9 \\
Sending weekly and monthly report to SACIDS & 0.9 \\
Total & 100 \\
For lack of collaboration & \\
No policy statement to enforce collaboration among & 42.8 \\
health experts & \\
No networking partners & 25.0 \\
Lack of knowledge about animal health expertise & 14.3 \\
Not planned at all & 7.1 \\
Because of poor health policy regarding zoonotic diseases & 3.6 \\
Lack of resources to facilitate collaboration & 3.6 \\
Ecology department was not involved & 3.6 \\
Total & 100 \\
\hline & \\
\hline
\end{tabular}


information sharing (17.8\%), more funds availability for zoonotic diseases $(11.3 \%)$, implementing the concept of One Health $(8.1 \%)$, multisectoral collaboration $(4.8 \%)$, and raising awareness among policy makers of the One Health concept $(3.2 \%)$. Moreover, each of the following three factors was mentioned by $1.6 \%$ of the 62 respondents as other factors enhancing collaboration among various health experts: all health experts being under one ministry, strong policy and constitution, and having magazines or books for medical and veterinary officers. Some salient points were made regarding these additional factors, such as the importance of raising awareness among policy makers of the One Health concept and strong policy and constitution. If these were done, they would contribute to the enhancement of One Health policy implementation, for example through budgeting for One Health activities at the ministerial and district levels. This idea is in line with that of Rushton et al. (2012), who argue that for diseases like brucellosis - which cause significant economic impact while the cost of controlling them in animals are greater than the benefits generated in the animal population, but the costs are exceeded when benefits from the prevention of the diseases in humans are taken into account - there is a need for One Health thinking at a much higher level of budgetary and resource allocation, so that control campaigns in animals are sufficiently financed to lead to benefits in humans.

\section{Extent to which barriers impede One Health practice}

The results presented in Table 3 show that the factors that mostly constrained collaboration were lack of consensus on priority-setting (65.0\%), inadequate resources for dissemination of results and raising public awareness $(64.8 \%)$, inadequate transport facilities for medical, veterinary and wildlife officers $(62.5 \%)$, and applied research being not recognised or rewarded as important as basic research (55.5\%). These four issues are related to the issues of planning and resource allocation discussed in the previous section.

The respondents were also asked to mention other factors which they thought constrained collaboration. These other factors were mentioned by 79 of the respondents: lack of team work among health experts $(17.7 \%)$, lack of relevant knowledge or skills needed for collaboration (11.4\%), poor communication among health experts $(10.1 \%)$, experts being based in different departments (10.1\%), and insufficient budget $(7.6 \%)$. The other factors were: selfishness of health experts not considering public benefits during collaboration $(6.3 \%)$, inconvenient time for the implementation of activities due to lack of resources (5.1\%), different health policies in human health sector and animal health sector (5.1\%), lack of collaborative budgeting for human and animal health (3.8\%), lack of common research on zoonotic diseases (3.8\%), weak facilitation $(3.8 \%)$, difference in knowledge and work ethics $(2.5 \%)$, different management of zoonotic diseases $(2.5 \%)$, and health experts not sharing their reports $(2.4 \%)$. Moreover, each of the following seven factors was mentioned by $1.3 \%$ of the respondents: shortage of personnel, applied research being not recognised or rewarded as basic research, confidentiality of medical data to be shared by veterinary and wildlife officers, authorities' lack of appreciation for experts, bureaucracy in implementing animal health and human health programmes, and health experts being not interested in the One Health concept.

The respondents were also asked to give their views on whether the collaboration existing among medical, veterinary and wildlife experts was enough for effective prevention, control and treatment of zoonotic diseases; about two-thirds (66.3\%) of them responded that it was not enough. They were then asked to give their views on how it should be improved. They made the following suggestions: making health experts of various disciplines work together $(22.5 \%)$, emphasising training to both experts $(18.3 \%)$, collaborative sharing of information from both sides $(11.3 \%)$, formulating policies for collaboration between human health and animal health sectors $(11.3 \%)$, conducting training to both experts on zoonotic diseases $(9.9 \%)$, sufficient budget to enable collaboration (9.9\%), conducting sharing experience meetings between human health experts and animal health experts (4.2\%), involving communities (2.8\%), and experts reaching consensus on improving collaboration among them $(2.8 \%)$. Moreover, each of the following suggestions were made by $1.4 \%$ of the respondents: transparency in implementation of One Health practice activities, availability of qualified staff at district level, finding a mechanism for each ministry to address zoonotic diseases depending on the source, both ministries allocating budgets for prevention of zoonotic diseases, recognition of the work done by experts, and each district conducting monthly meetings to implement the One Health concept.

The suggestions given by the respondents for improving collaboration among health experts were generally consistent with their views on the extent to which general factors enhance collaboration. For example, common training in zoonotic diseases for both veterinary and medical doctors and fieldworkers ranked second among general factors enhancing collaboration, and the same issue of training ranked second among the suggestions for improvement of collaboration among health experts.

\section{Actual factors that enhanced and impeded collaboration}

The factors enhancing and those impeding collaboration among medical, veterinary and wildlife officers were evaluated further by asking the respondents about the actual factors that were applicable to their situation; those who had collaborated listed the factors that had enabled them to collaborate, and those who had not collaborated listed the factors that had prevented them from collaborating. These factors are discussed below.

\section{Actual factors that enhanced collaboration}

As seen in Table 4, the leading factors that enhanced collaboration among various health experts were the disease(s) being a zoonosis or zoonoses which needed 
assistance from veterinarians (26.4\%), the disease(s) being a zoonosis or zoonoses which needed assistance from medical doctors $(25.5 \%)$, being instructed by upper-level leaders to cooperate with other health experts $(22.7 \%)$, and the availability of funding for the collaboration (19.8\%). The first two of the above-mentioned factors relate to the issue of common training. This issue is being addressed by organisations promoting One Health on a long-term basis, such as SACIDS, which has established postgraduate training in One Health, starting with an M.Sc. (One Health Molecular Biology) at the Sokoine University of Agriculture in Tanzania and an M.Sc. (One Health Analytical Epidemiology) at the University of Zambia. Related training in One Health has also been initiated by several other universities, for example the University of Calgary in Canada (Zinsstag et al. 2012). The other two factors relate to the issues of planning and budgeting discussed in the previous section.

Further analysis of the results focused on the ways in which respondents had collaborated. The leading ways of collaboration were: disease treatment or control (17.1\%), campaigns against specific diseases $(15.2 \%)$, disease diagnosis $(14.6 \%)$, disease surveillance $(14.6 \%)$, and treatment or control of rabies $(10.4 \%)$. The other ways in which respondents had collaborated were: conducting campaigns against rabies $(9.8 \%)$, surveillance of rabies $(7.9 \%)$, diagnosing rabies $(7.3 \%)$, research $(2.4 \%)$, and sending weekly and monthly reports to relevant authorities $(0.6 \%)$.

With regard to other diseases, collaboration pertained to only some aspects, and not to all aspects as with regard to rabies. Other diseases that elicited collaboration were: anthrax diagnosis, surveillance, treatment and campaigns; Rift Valley Fever (RVF) diagnosis, surveillance, treatment and campaigns; East Coast Fever (ECF) diagnosis, surveillance, treatment and campaigns; contagious bovine pleuropneumonia (CBPP) diagnosis, surveillance, treatment and campaigns; PPR diagnosis; tuberculosis diagnosis, surveillance, treatment and campaigns; brucellosis diagnosis, surveillance, treatment and campaigns; and trypanosomiasis surveillance.

The financial supporters of the collaborative activities were parent ministries, especially the Ministry of Health and Welfare, the Ministry of Livestock and Fisheries and the Ministry of Natural Resources and Tourism, and various national and international organisations, including FAO, WHO, TASAF, TAWIRI, NCAA, NDC, SAIDS, TANAPA, the Bill and Melinda Gates Foundation, local government authorities, SUA and MUHAS.

Respondents were also asked about the outcomes of their collaborations; however, only 27 of them responded to this question. They said that disease outbreaks were effectively controlled (48.1\%) and that more people became aware of disease control and treatment (14.9\%). Others (3.7\%) said that the diseases were diagnosed and controlled; they succeeded to collect data about rinderpest; dogs were vaccinated against rabies; awareness about rabies was increased among community members; and community members were given more knowledge on how to prepare meat before consuming it.

\section{Actual factors that impeded collaboration}

The leading factors that impeded collaboration among various health experts (see Table 4) were the following: lack of policy statements to enforce collaboration among health experts $(42.8 \%)$, lack of networking partners $(25.0 \%)$, lack of knowledge of animal health expertise (14.3\%), and lack of plans for collaboration $(7.1 \%)$. Some solutions to these salient issues have been discussed above, with the exception of networking. Networking would be promoted through the formulation of guidelines and memoranda of understanding for collaboration among various health experts.

\section{Conclusions and recommendations}

The proportion of medical, veterinary and wildlife officers collaborating with experts in fields different from theirs are encouraging in view of the fact that there are no guidelines for collaboration. The assumption is that if there were guidelines for collaboration, the level of collaboration would be higher. In view of this, it is recommended that efforts be made to increase the proportion of medical, veterinary and wildlife officers collaborating in order to control lingering (neglected) zoonoses and relatively new diseases more effectively.

The results of this study showed that respondents were able to rank general bridges for and barriers to collaboration and even add others. This implies that they are familiar with the different factors that enhance or impede collaboration among health experts. On the basis of this, it is recommended that health ministries work together to address impediments to collaboration among them and formulate regulations and memoranda of understanding for mainstreaming One Health approaches in human and animal health systems, so as to increase collaboration. In view of the argument presented in the introduction that the FAO, OIE and WHO could facilitate national efforts to increase sectoral collaboration in order to address health risks, especially at the animal-humanecosystems interface, country-specific factors and FAO, OIE and WHO initiatives and support should be considered when mainstreaming One Health approaches in human and animal health systems.

Based on the findings of this study, the general bridges for and barriers to collaboration documented in literature hold true in practice. The following bridges were more relevant in this study: some diseases are zoonoses which need assistance from health experts from different fields, existence of funding for the collaboration, disease outbreaks, and availability of transport facilities. The following barriers to collaboration were prominent: lack of policy statement to enforce collaboration among experts, lack of networking partners, lack of knowledge about animal health expertise, and lack of plans for collaboration. Therefore, efforts to bring about collaboration should give priority to these factors. 


\section{Acknowledgements}

The authors thank the Wellcome Trust Grant WT087546MA to the Southern African Centre for Infectious Disease Surveillance (http://www.sacids.org) and its collaborating UK partner institutions, namely the London School of Hygiene and Tropical Medicine (http://www.lshtm.ac.uk), the Royal Veterinary College (http://www.rvc.ac.uk) and the London International Development Centre (http:// www.lidc.org.uk), for supporting this work technically and financially. Also, the authors thank the respondents for giving of their precious time to fill in the questionnaire that was used for data collection.

\section{Competing interests}

The authors declare that they have no financial or personal relationship(s) that may have inappropriately influenced them in writing this article.

\section{Authors' contributions}

K.A.K. (Sokoine University of Agriculture) designed and conducted the research and drafted the article. A.D.K. (Muhimbili University College of Health and Allied Sciences) and D.M.K. (Sokoine University of Agriculture) were the primary mentors or supervisors; they provided input to improve the research process and the article. E.L. (Muhimbili University College of Health and Allied Sciences), R.C. (London School of Hygiene and Tropical Medicine) and J.R. (Royal Veterinary College) were mentors or supervisors; they provided critical comments from time to time. R.K. (Royal Veterinary College) was an advisor or collaborator; he read the manuscript and provided critical comments.

\section{References}

AHEAD, n.d., What is AHEAD?, viewed 06 June 2011, from http://www.wcs-ahead. org/index.html
Brazier, J., Ratcliffe, J., Salomon, J.A. \& Tsuchiya, A., 2007, Measuring and valuing health benefits for economic evaluation, Oxford University Press, Oxford.

Coker, R., Atun, R. \& McKee, M., 2008, Health systems and the challenge of communicable diseases: Experiences from Europe and Latin America, Open University Press, Berkshire.

FAO, OIE \& WHO, 2010, The FAO-OIE-WHO Collaboration: Sharing responsibilities and coordinating global activities to address health risks at the animal-humanecosystems interfaces: A tripartite concept note viewed 13 December 2013 from http://www.who.int/influenza/resources/documents/tripartite_concept_note hanoi/en/

Federation of Veterinarians of Europe (FVE), n.d., The Federation of Veterinarians of Europe, viewed 06 June 2011, from http://www.fve.org/about_fve/index.php

Karimuribo, E.D., Sayalel, K., Beda, E., Short, N., Wambura, P., Mboera, L.G. et al., 2012, 'Towards One Health disease surveillance: The Southern African Centre for Infectious Disease Surveillance approach', Onderstepoort Journal of Veterinary Research 79(2), Art. \#454, viewed 07 June 2013, from http://dx.doi.org/10.4102/ ojvr.v79i2.454

Mazet, J.A.K., Clifford, D.L., Coppolillo, P.B., Deolalikar, A.B., Erickson, J.D. \& Kazwala, R.R., 2009, 'A "One Health" approach to address emerging zoonoses: The HAL project in Tanzania', PLOS Medicine 6(12), viewed 25 June 2013, from http://www. prosmedicine.org/article/info\%3Adoi\%2F10.1371\%2Fjournal.pmed.1000190

Monath, T. P., Kahn, L. H. \& Kaplan, B., 2010, 'Introduction: One Health perspective', ILAR Journal 51(3), 192-198, viewed on 25 June 2013, from http://www.ncbi.nIm. nih.gov/pubmed/21131719.

One Health Initiative, 2011, One Health news, viewed 21 August 2011, from http:// www.onehealthinitiative.com/news_archived.php

Riedel, S., 2005, 'Edward Jenner and the history of smallpox and vaccination', Proceedings (Baylor University Medical Center 18(1), 21-25, viewed 23 May 2011, from http://www.ncbi.nlm.nih.gov/pmc/articles/PMC1200696

Rushton, J., Häsler, B., De Haan, N. \& Rushton, R., 2012, 'Economic benefits or drivers of a 'One Health' approach: Why should anyone invest?', Onderstepoort Journa of Veterinary Research 79(2), Art. \#461, viewed 22 June 2013, from http://dx.doi. org/10.4102/ojvr.v79i2.461

SACIDS, n.d., What we do, viewed 21 June 2013, from http://www.sacids.org/kms/ frontend/?m=8

Schwabe, C.W., 1969, Veterinary medicine and human health, 2nd edn., Williams \& Wilkins, Baltimore.

Winding, W., 2007, One Health: Pulling animal health and public health together, viewed 30 May 2011, from http://www.fve.org/news/presentations/one_health_ concept.ppt

World Bank, 2010, People, pathogens and our planet, volume 1: Towards a One Health approach for controlling zoonotic diseases. Report No. 50833-Glb, World Bank, Agriculture and Rural Development Health, Nutrition and Population, Washington DC.

World Health Organization (WHO), 2006, 'The control of neglected zoonotic diseases: A route to poverty alleviation', in Report of a Joint WHO/DFID-AHP Meeting with the participation of FAO and OIE, Geneva, 20-21 September, viewed 31 May 2011 from http://whqlibdoc.who.int/publications/2006/9789241594301_eng.pdf

Zinsstag, J., Meisser, A., Schelling, E., Bonfoh, B. \& Tanner, M., 2012, 'From 'two medicines' to 'One Health' and beyond', Onderstepoort Journal of Veterinary Research 79(2), Art. \#492, viewed 07 June 2013, from http://dx.doi.org/10.4102/ ojvr.v79i2.492 